\title{
Functional fitness and bone mineral density in the elderly
}

\author{
Élvio R. Gouveia • José A. Maia • Gaston P. Beunen • \\ C. J. R. Blimkie • António L. Rodrigues • \\ Duarte L. Freitas
}

Received: 18 May 2011 / Accepted: 14 February 2012/Published online: 12 April 2012

(C) International Osteoporosis Foundation and National Osteoporosis Foundation 2012

\begin{abstract}
Summary Bone quality has been associated with genetic factors and several environmental influences. This study suggests that although functional fitness should be considered in clinical assessments of bone health, body composition appears to have a higher relevance in the explanation of bone health/strength in older people.

Purpose This study aims to describe the association between functional fitness (FF), other constitutive factors, and bone health/strength in a large community-dwelling sample of elderly active Portuguese.

Methods This cross-sectional study included 401 males and 401 females aged 60-79 years old. Bone mineral density (BMD) of the total body, lumbar spine (LS), and hip region
\end{abstract}

É. R. Gouveia $(\bowtie) \cdot$ D. L. Freitas

Department of Physical Education and Sports,

University of Madeira,

Campus Universitário da Penteada,

9000-390 Funchal, Portugal

e-mail: erubiog@uma.pt

J. A. Maia

CIFI2D and Faculty of Sport, University of Porto,

Porto, Portugal

G. P. Beunen

Department of Biomedical Kinesiology, Faculty of Kinesiology and Rehabilitation Sciences, Katholieke Universiteit Leuven,

Leuven, Belgium

\section{J. R. Blimkie}

Department of Kinesiology, Faculty of Science,

McMaster University,

Hamilton, ON, Canada

A. L. Rodrigues

Private Clinic Santa Catarina,

Funchal, Portugal was determined by dual-energy X-ray absorptiometry (DXA). In addition, femur strength index (FSI) was determined. FF was assessed using the Senior Fitness Test. Demographic information and a health history were obtained by telephone interview through questionnaire.

Results Aerobic endurance and body strength were positively related with hip BMD region in males $(0.10<r<$ $0.16 ; p<0.01-0.05)$ and females $(0.13<r<0.28 ; p<$ $0.01)$. No significant correlation was found between any FF test and LS BMD, except for upper-body strength in females. After controlling for other constitutive predictors (sex, age, height, body mass (BM), total fat mass (TFM), and total lean tissue mass (TLTM)), FF had a minor contribution only in prediction of BMD at multisites and FSI. The total explained variance for all determinants was moderate $\left(R^{2}=0.35\right.$ for femoral neck (FN) BMD, $R^{2}=0.27$ for LS BMD, $R^{2}=0.49$ total body $\mathrm{BMD}$, and $R^{2}=0.22$ for FSI).

Conclusions Sex, age, height, BM, TLTM, and TFM entered as the most significant contributors for BMD and FSI. Although FF parameters are typically considered in clinical assessments of bone health/strength in older people, body composition appears to have a higher relevance in the explanation of BMD and strength.

Keywords Aging · Bone mineral density · Functional fitness $\cdot$ Femur strength index

\section{Introduction}

Osteoporosis is a disease characterized by low bone mineral density (BMD), microarchitectural bone tissue deterioration and increased fracture risk [1]. Bone fractures resulting from osteoporosis seem to be a major worldwide health concern. 
In fact, demographic patterns and secular trends suggest that this problem will increase in the next few years [2].

Bone mass is mainly genetically determined [3]. However, because bones adapt to the forces they support [4], bone quality also depends on environmental and lifestyle factors [5] such as physical activity (PA) and nutrition, e.g., calcium intake [6]. Currently, most clinicians, dealing with established vertebral and hip osteoporosis, focus their attention on BMD, and rarely consider fall prediction or prevention. However, the treatment of osteoporosis is moving forward and nowadays its prevention seems to be gaining importance [2]. Indeed, the risk of fracture is influenced by both bone strength and falls. Measures of functional fitness (FF) and performance are predictors of falls, and both BMD and physical performance are independent predictors of fracture risk $[7,8]$.

The evidence relating variations in PA and fitness levels to BMD in healthy older people is inconclusive. Theoretically, it has been postulated that skeletal muscle contraction forces generate large reaction forces during normal activity and such forces are thought to have local trophic or adaptive effects on bone mass. Recently, it has been shown that physical fitness is associated with BMD in older populations $[9,10]$. However, others have confirmed the association between physical fitness and BMD only in women [11, 12] whereas other authors failed to find any association either in women [11, 13] or in men [14]. Generally, there are relatively limited published data about this issue in men. Evidence suggests that reduced body weight $[15,16]$, total lean tissue mass (TLTM), and total fat mass (TFM) [16, 17], reduced levels of PA [18, 19], general frailty and poor balance $[10,20]$, low body strength $[20,21]$, and low aerobic endurance $[22,23]$ are risk factors for bone health/ strength and increased fractures.

The main purpose of this study was to describe the association between muscular strength, aerobic endurance, balance, and bone health/strength in a large Portuguese sample of active community-dwelling elderly men and women. We hypothesize that FF measures are associated with BMD at the total body, lumbar spine (LS), femoral neck (FN), Ward's triangle, trochanter and total hip, and with femur strength index (FSI) even after controlling for constitutive factors (age, sex, height, body mass, and body composition).

\section{Methods}

Study design and subjects

Participants are part of the research project entitled "Health and quality of life of older adults from Autonomus Region of Madeira (ARM), Portugal". In total, 802 community- dwelling elderly active Portuguese, 401 men and 401 women, aged between 60 and 79 years were evaluated in 2008/ 2009. Participants were sufficiently independent to visit the Laboratory of Human Physical Growth and Motor Development at the University of Madeira (UMa) on their own. All participants were able to complete the Senior Fitness Test. We excluded participants $(0.75 \%$ of people who volunteered for the study) with metal prostheses in the femur or lumbar spine. Proportional regional (geographic) representation was determined by stratified sampling, based on Census 2001 data [24], with the number of subjects per age cohort and sex serving as stratification factors. Subjects were volunteers recruited via advertisements for a large study on bone health and FF in newspapers, churches, senior groups, and senior centers throughout the ARM.

The study was approved by UMa, the Regional Secretary of Education and Culture, and the Regional Secretary of Health. All participants were informed about the nature and purposes of the study and written informed consent was obtained from each subject.

\section{Anthropometry and bone densitometry}

Body mass (BM; kilogram) was measured with a balance scale accurate to $0.1 \mathrm{~kg}$ (Seca alpha digital scales model 770, Germany) and standing height (centimeter) with a Holtain stadiometer (Holtain Ltd., Crymych, UK) accurate to $0.1 \mathrm{~cm}$. Subjects wore light, indoor clothing without shoes during the measurements.

BMD (gram per square centimeter) was determined by dual-energy X-ray absorptiometry (DXA; Lunar Prodigy Primo, with technologic fan beam-GE Healthcare, Encore 2007 software version 11.40.004). After removing all objects suspected or known to contain metal, participants were positioned by the technician according to the manufacturer's recommended protocol. Subjects were in a supine position and the following sites were investigated: total body, LS (anterior-posterior), and left femur (FN, trochanter, Ward's triangle, and total femur). In addition, the scans yielded information on body composition, including TLTM and TFM.

In addition to the conventional densitometry measurements, structural variables were also determined using the Hip Strength Analysis program, including hip axis length and cross-sectional moment of inertia. These bone geometry variables were used to calculate the FSI, the ratio of estimated compressive yield strength of the FN to the expected compressive stress of a fall on the greater trochanter adjusted for each subject's age, height, and BM [25].

Scans were standardized daily against a calibration phantom; the precision error expressed as the coefficient of variation $(\mathrm{CV} \%)$ was $0.31 \%$. Scans were taken alternately by four different technicians over the course of data 
collection. All technicians received an identical 5-day DXA training course before the start the study using the manufacturer's recommended protocol. Reliability of our DXA measurements was determined on a subsample of 17 males and females aged $69.3 \pm 5$ years. Technicians were paired and members of each pair performed separate LS and hip scans on half the subjects each (nine and eight subjects, respectively, per pair). Subjects were repositioned after every scan. Results from both pairs of assessors were pooled and the technical error of the measurements was determined. These values ranged from $0.19 \%$ for total hip to $0.50 \%$ for the LS. Inter-observer reliability using the CV\% was 1.72 , $2.10,2.53$, and $0.88 \%$ for LS, FN, Ward's triangle, and total hip, respectively.

\section{Functional fitness}

FF was assessed with the Senior Fitness Test (SFT) [26]. To maximize the consistency of assessment procedures, training sessions were conducted with five graduates in Physical Education and Sport, one in Nursing and three in Senior Education. First, a theoretical explanation of the protocols was provided for all research and field team members based on a standard testing manual and a videotape describing all test procedures [26]. Second, FF tests were selfadministered among team members. Third, training sessions was done with older adults. The preparation of the field team was completed with a pilot study in 50 older adults aged between 60 and 79 years.

The pilot study was carried out in UMa and all subjects were measured twice with an interval of 1 week. Table 1 contains the test-retest reliability for each test item in the pilot study, which was established by calculating the intraclass correlation coefficient $(R)$. Correlation coefficients were between 0.75 for the 8 -ft up-and-go test $(95 \% \mathrm{CI}$ : $0.56,0.86$ ) and 0.88 for the 6 -min walk test ( $95 \%$ CI: 0.79 , 0.93 ), indicating acceptable levels of reliability for all FF tests. Inter-observer reliability was also determined using the CV. The CV\% was between $2.10 \%$ (in the 6-min walk test and the 8-ft up-and-go test) and $2.6 \%$ (in chair stand test) for the first measurements (test). For second measurements (retest), the $\mathrm{CV}$ ranged between $1.70 \%$ (in the 6-min walk test) and $2.4 \%$ (in the 8-ft up-and-go test).
All participants received the same instructions about the procedures for each test and completed one or two trials to become familiarized with the task. Testing stations were arranged in the following order to minimize the effects of fatigue: the chair stand test (lower body strength), arm curl test (upper body strength), chair sit and reach test (lower body flexibility), back scratch test (upper body flexibility), and 8-ft up-and-go test (agility/dynamic balance). The 6min walk test (aerobic endurance) was administered after all other tests and questionnaires had been completed. The flexibility tests were not included in the statistical analysis. A detailed description of the evaluation procedures, namely, equipment, procedure, scoring, and safety precautions can be found in the SFT manual [26].

Health questionnaire and nutritional habits

Demographic information and a health history were obtained by telephone interview. A modified version of the health questionnaire employed in the FallProof! Programme [27], was used to assess behavior and lifestyle characteristics, including smoking history, history of degenerative diseases and osteoarthritis, fracture history, current, and past therapy with specific classes of medications including hormones (estrogen and thyroid), calcium supplements, aspirin, vitamin $\mathrm{D}$, anxiolytic drugs, and sleeping aids.

Dietary intake was estimated using a previously validated [28] semiquantitative food frequency questionnaire developed by the Department of Hygiene and Epidemiology of Porto University Medical School. This questionnaire included 86 food items, including those with high contribution for the intake of dietary calcium such as dairy products (e.g., milk, cheese, ice cream, and yogurts), as well as leafy green vegetables and fish. In addition, this questionnaire assessed caffeine and alcohol intake (combination of consumption of wine, beer, and liquor drinks). Food consumption was converted into nutrients by the software Food Processor Plus ${ }^{\circledR}$ (ESHA Research, Salem, Oregon, USA, 1997), which has been adapted to Portuguese traditional food and dishes [28].

Statistical analyses

Descriptive characteristics of subjects were reported as means \pm SDs. Exploratory analysis of the data took place
Table 1 Mean, standard deviation, coefficient of variation (CV), intraclasse correlation (ICC), and confidence intervals (IC) for motor tests between test and retest in pilot study

\begin{tabular}{lccccccc}
\hline & $N$ & $\begin{array}{l}\text { Test } \\
\text { Mean } \pm \text { SD }\end{array}$ & CV & $\begin{array}{l}\text { Retest } \\
\text { Mean } \pm \text { SD }\end{array}$ & CV & ICC & IC (95 \%) \\
\hline Chair stand test (reps) & 49 & $17.6 \pm 4.6$ & 0.26 & $18.5 \pm 3.9$ & 0.21 & 0.77 & $0.59-0.87$ \\
Arm curl test (reps) & 50 & $22.8 \pm 5.7$ & 0.25 & $24.2 \pm 5.3$ & 0.22 & 0.89 & $0.82-0.94$ \\
8-Ft up-and-go test (sec) & 50 & $4.9 \pm 1.0$ & 0.21 & $4.8 \pm 1.1$ & 0.24 & 0.86 & $0.75-0.92$ \\
6-Min walk test (m) & 49 & $567.4 \pm 116.9$ & 0.21 & $575.6 \pm 95.1$ & 0.17 & 0.78 & $0.62-0.88$ \\
\hline
\end{tabular}


through the usual procedures for identifying outliers and tested for normality by the Kolmogorov-Smirnov statistic. If required, non-normal distributed characteristics were appropriately transformed using $\log 10$, square root or inverse transform functions. Differences of means, within each sex and across age intervals, were performed with analysis of variance (ANOVA).

Sex-specific bivariate associations between bone health indicators (BMD and FSI) and putative predictors of bone health/strength (age, height, BM, TLTM, TFM, PA, FF parameters, fracture history, dietary calcium, medication consumption, and smoking) were calculated for all age cohorts combined using Pearson product-moment correlation coefficient.

Multiple linear regression (MLR) analysis was then used to identify the contribution of the predictors for BMD (FN, LS, and total body) and FSI. Betas, namely standardized regression coefficients, were used to assess the relative independent contributions of each predictor and the $R^{2} \mathrm{~s}$ to indicate the percentage of variance accounted for by the predictors for each BMD site and FSI separately. The standard MLR was used, with all predictors entered in the equation simultaneously. The selection of the putative predictors' sex, age, height, BM, TLTM, TFM, and FF tests (chair stand test, arm curl test, 6-min walk test, and 8-ft upand-go test) was based on known key important predictors previously identified in the literature, and the strength and significance of the zero-order correlations in the preliminary analysis. The level of significance was set at $p<0.05$. Analyses were performed using SPSS, version 18.0. [29]

\section{Results}

Table 2 contains a summary of the subjects' characteristics by sex and age cohort. Results from the ANOVAs revealed that differences between age cohorts were significant $(p<$ 0.05 ) for height, TLTM, upper and lower body strength, aerobic endurance, and balance, in both genders. Medication consumption showed significant age cohort differences in men and BM in women only.

Sex-specific correlations for all age cohorts combined between FSI, BMD at multiple body sites, and subjects' characteristics are presented in Table 3. With the exception of LS BMD and FSI for males, all BMD sites were significantly negatively correlated with age, in men and women. BMD at all sites was significantly positively correlated at the $p<0.01$ level, with height $(0.158<r<0.279$ and $0.314<r$ $<0.426)$, BM $(0.158<r<0.279$ and $0.314<r<0.426)$, TFM $(0.190<r<0.319$ and $0.245<r<0.486)$, and TLTM $(0.179<$ $r<0.389$ and $0.221<r<0.477)$ in men and women, respectively. The relationship between FF parameters and BMD in females was positive and stronger than for males. Aerobic endurance and upper and lower body strength in both men and women, and balance, only in women, were positively correlated with BMD at all sites for the femur (FN, trochanter, Ward's triangle, and total hip). No significant correlation was found between FF parameters and LS BMD.

There was a significant negative correlation between FSI and age, in women but not men, between FSI and height, in men but not in women, and between FSI and BM, TFM and TLTM, in both genders. FSI was significantly positively correlated with endurance and balance in women and with lower body strength in both genders. Fracture history and BMD at all sites, were negatively correlated $(-0.201<$ $r \leq 0.143$, and $-0.220<r \leq 0.166 ; p<0.01$ ) in men and women, respectively. Fracture history and FSI were negatively correlated only in women $(r=-0.15 ; p<0.01)$.

In the MLR analyses, the contributions of sex, age, height, BM, TLTM, TFM, and FF tests in explaining variation in BMD at multiple sites and FSI was investigated. The contributions of the putative predictors of BMD and FSI are provided in Tables 4, 5, 6, and 7.

For FN, LS, and total body BMD and FSI, sex, BM, and height were the most important predictors, followed by TLTM (for LS BMD), age (for FN and total body BMD), and TFM (for FSI). With the exception of upper body strength for FN BMD, and lower body strength for FSI, none of the FF tests were associated with BMD at any other site or with FSI. Betas were negative for sex and age, indicating that women and older people had lower BMD and FSI. The total explained variance was moderate $R^{2}=$ $0.35, R^{2}=0.27$, and $R^{2}=0.49$ for FN BMD, LS BMD, and total body BMD, respectively. The total explained variance of FSI was lower $\left(R^{2}=0.22\right.$; Tables $4,5,6$, and 7).

\section{Discussion}

This study was conducted to assess the association between muscular strength, aerobic endurance, balance, and bone health/strength in a large Portuguese sample of active community-dwelling elderly men and women. Our findings indicate that almost all FF tests are associated with most BMD body sites and FSI. However, these associations vanish mostly, with few exceptions, when size and body composition are taken into account in MLR analysis.

Our findings in part, agree with previous cross-sectional and longitudinal studies of similar aged populations. Blain et al. [21] found that high FN and LS BMD were significantly associated with higher values of quadriceps strength ( $r=0.55, p<0.001$ and $r=0.36, p<0.01)$, respectively, in women aged 60 years and over. Data from a relatively large study by Taaffe et al. [10] of black and white men and women with an approximate sample size similar to ours 
Table 2 Age and sex-specific descriptive characteristics (means and SD)

Age groups (years)

\begin{tabular}{|c|c|c|c|c|}
\hline $60-64(1)$ & $65-69(2)$ & $70-74(3)$ & $75-79$ (4) & Contrast \\
\hline Mean \pm SD & Mean \pm SD & Mean \pm SD & Mean \pm SD & $p$ \\
\hline
\end{tabular}

\begin{tabular}{|c|c|c|c|c|c|c|}
\hline \multicolumn{7}{|l|}{ Men } \\
\hline Height $(\mathrm{cm})$ & $166.9 \pm 5.2$ & $165.9 \pm 6.2$ & $164.5 \pm 6.1$ & $164.6 \pm 6.2$ & 0.011 & $1<2,3,4$ \\
\hline $\mathrm{BM}(\mathrm{kg})$ & $80.3 \pm 12.1$ & $79.7 \pm 13.1$ & $79.9 \pm 13.3$ & $75.8 \pm 13.0$ & 0.058 & - \\
\hline TFM (kg) & $22.6 \pm 8.1$ & $23.3 \pm 7.9$ & $23.6 \pm 8.6$ & $21.5 \pm 8.2$ & 0.285 & - \\
\hline TLTM $(\mathrm{kg})$ & $54.3 \pm 5.9$ & $53.3 \pm 5.8$ & $52.8 \pm 5.5$ & $51.2 \pm 6.3$ & 0.003 & $4>3,2,1$ \\
\hline Chair stand test (reps) & $15.7 \pm 4.1$ & $14.8 \pm 4.0$ & $13.4 \pm 4.0$ & $12.6 \pm 3.1$ & $<0.001$ & $1,2<3,4$ \\
\hline Arm curl test (reps) & $17.7 \pm 3.7$ & $17.3 \pm 4.1$ & $15.8 \pm 3.9$ & $14.9 \pm 2.8$ & $<0.001$ & $1,2<3,4$ \\
\hline 6-Min walk test (m) & $577.9 \pm 93.7$ & $526.9 \pm 115.7$ & $512.3 \pm 105.9$ & $461.8 \pm 108.6$ & $<0.001$ & $1<2,3,4 ; 4>3,2,1$ \\
\hline 8-Ft up-and-go (sec) & $4.8 \pm 1.5$ & $5.4 \pm 2.1$ & $5.9 \pm 2.1$ & $6.9 \pm 3.2$ & $<0.001$ & $3>1 ; 4>3,2,1$ \\
\hline Calcium (mg/day) & $721.7 \pm 321.7$ & $743.7 \pm 365.2$ & $723.9 \pm 350.6$ & $734.5 \pm 384.9$ & 0.969 & - \\
\hline Medication (units) & $2.3 \pm 2.1$ & $3.0 \pm 2.4$ & $3.6 \pm 2.7$ & $3.1 \pm 2.2$ & 0.006 & $3>1$ \\
\hline Fracture history (\%) & 28.9 & 32.9 & 21.6 & 18.5 & - & - \\
\hline Smoking (\%) & 17.8 & 6.7 & 10.8 & 7.6 & - & - \\
\hline \multicolumn{7}{|l|}{ Women } \\
\hline Height $(\mathrm{cm})$ & $154.2 \pm 5.4$ & $153.8 \pm 5.5$ & $152.0 \pm 5.8$ & $150.1 \pm 5.4$ & $<0.001$ & $4,3>1 ; 4>2$ \\
\hline $\mathrm{BM}(\mathrm{kg})$ & $72.2 \pm 11.7$ & $71.2 \pm 12.7$ & $70.6 \pm 10.6$ & $67.8 \pm 11.5$ & 0.063 & $4>3,2,1$ \\
\hline TFM (kg) & $29.7 \pm 7.8$ & $28.7 \pm 8.0$ & $28.2 \pm 7.3$ & $27.1 \pm 7.8$ & 0.131 & - \\
\hline TLTM $(\mathrm{kg})$ & $39.9 \pm 4.9$ & $40.0 \pm 5.5$ & $39.3 \pm 3.9$ & $38.2 \pm 4.3$ & 0.033 & $4>2$ \\
\hline Chair stand test (reps) & $14.8 \pm 4.7$ & $13.2 \pm 4.2$ & $12.8 \pm 3.7$ & $11.5 \pm 3.4$ & $<0.001$ & $4,3>1 ; 1<2$ \\
\hline Arm curl test (reps) & $16.8 \pm 4.3$ & $16.3 \pm 4.8$ & $16.0 \pm 4.3$ & $14.8 \pm 4.0$ & 0.013 & $1<2,3,4$ \\
\hline 6-Min walk test (m) & $502.6 \pm 97.0$ & $474.8 \pm 110.1$ & $452.7 \pm 98$ & $392.8 \pm 118.2$ & $<0.001$ & $4>3,2,1 ; 3>1$ \\
\hline 8-Ft up-and-go (sec) & $5.2 \pm 1.4$ & $6.0 \pm 1.7$ & $6.5 \pm 2.4^{b}$ & $7.7 \pm 3.6$ & $<0.001$ & $4>3,2,1 ; 3>1$ \\
\hline Calcium (mg/day) & $906.5 \pm 387.3$ & $817.9 \pm 381.2$ & $821.8 \pm 398.6$ & $796.5 \pm 384.5$ & 0.197 & - \\
\hline Medication (units) & $3.5 \pm 2.8$ & $4.5 \pm 2.8$ & $4.3 \pm 2.3$ & $4.3 \pm 2.4$ & 0.060 & - \\
\hline Fracture history (\%) & 26.5 & 24.7 & 39.0 & 36.9 & - & - \\
\hline Smoking (\%) & 3.6 & - & 1.2 & - & - & - \\
\hline
\end{tabular}

$1<2,3,4,60-64$ age group is lower than $65-69,70-74$, and 75-79 age groups; 4>3, 2, 1, 75-79, age group is higher than 70-74, 65-69, 60-64 age groups; $1,2<3,4,60-64$, and 65-69 age groups are lower than 70-74 and 75-79 age groups; 3>1, 65-69 age group is higher than60-64 age group; 4, 3>1, 75-79, and 70-74 age groups are higher than 60-64 age group; 4>2, 75-79 age group are higher than 65-69 age group; $1<2,60-64$ age group is lower than $65-69$ age group

$S D$ standard deviation, $B M$ body mass, TFM total fat mass, TLTM total lean tissue mass

corroborate our findings, and reported a weak, but positive correlation between chair-rise performance and FN BMD.

Opposite results were found by Lindsey et al. [13] in older women $(68.3 \pm 6.8$ years $)$. The timed sit-to-stand test did not correlate significantly with BMD of the total body, LS, FN, Ward's triangle, trochanter, shaft, or total hip. Recently, Marin et al. [30] confirmed these results by failing to find any association between 30-s chair stand and LS, FN, or total body BMD. In older men, Miller et al. [14] concluded that total body, LS, pelvis, arm, and leg BMD did not correlate with lower body strength, measured as knee extensor strength. Similar results were reported by Stewart et al. [12] in older men and women for LS BMD. Our study found a site-specific association between lower muscular strength and BMD at the hip.
Reduced lower body strength has been strongly associated with hip fracture risk. Cawthon et al. [20], in a MLR analyses, showed that men who were unable to complete five consecutive chair stands were much more likely to suffer a hip fracture than those who completed the measure in the fastest time. The association between FSI, a derived measure that provides an estimative of hip fracture risk, and lower body strength was only moderate in our study. We found a small negative correlation between FSI and fracture history, but only in women $(r=-0.16, p<0.01)$. On the other hand, our MLR analyses confirmed that among FF tests, lower body strength contributed most to the explained variation in FSI $(\beta=0.083, p<0.042)$ after controlling for the variance explained by all other variables in the model. 
Table 3 Sex-specific Pearson correlations between BMD indicators, FSI, and selected descriptive characteristics

\begin{tabular}{|c|c|c|c|c|c|c|c|}
\hline Variables & $\begin{array}{l}\text { T. Body } \\
\text { BMD }\left(\mathrm{g} / \mathrm{cm}^{2}\right)\end{array}$ & $\begin{array}{l}\text { LS } \\
\operatorname{BMD}\left(\mathrm{g} / \mathrm{cm}^{2}\right)\end{array}$ & $\begin{array}{l}\text { FN } \\
\text { BMD }\left(\mathrm{g} / \mathrm{cm}^{2}\right)\end{array}$ & $\begin{array}{l}\text { Trochanter } \\
\text { BMD }\left(\mathrm{g} / \mathrm{cm}^{2}\right)\end{array}$ & $\begin{array}{l}\text { Ward's T. } \\
\text { BMD }\left(\mathrm{g} / \mathrm{cm}^{2}\right)\end{array}$ & $\begin{array}{l}\text { T. Hip } \\
\text { BMD }\left(\mathrm{g} / \mathrm{cm}^{2}\right)\end{array}$ & FSI \\
\hline \multicolumn{8}{|l|}{ Men } \\
\hline Age (years) & $-0.11^{\mathrm{b}}$ & - & $-0.26^{\mathrm{a}}$ & $-0.16^{\mathrm{a}}$ & $-0.24^{\mathrm{a}}$ & $-0.20^{\mathrm{a}}$ & - \\
\hline Height $(\mathrm{cm})$ & $0.28^{\mathrm{a}}$ & $0.16^{\mathrm{a}}$ & $0.26^{\mathrm{a}}$ & $0.20^{\mathrm{a}}$ & $0.18^{\mathrm{a}}$ & $0.19^{\mathrm{a}}$ & $-0.15^{\mathrm{a}}$ \\
\hline $\mathrm{BM}(\mathrm{kg})$ & $0.43^{\mathrm{a}}$ & $0.29^{\mathrm{a}}$ & $0.31^{\mathrm{a}}$ & $0.33^{\mathrm{a}}$ & $0.24^{\mathrm{a}}$ & $0.32^{\mathrm{a}}$ & $-0.34^{\mathrm{a}}$ \\
\hline TFM (kg) & $0.32^{\mathrm{a}}$ & $0.29^{\mathrm{a}}$ & $0.23^{\mathrm{a}}$ & $0.25^{\mathrm{a}}$ & $0.19^{\mathrm{a}}$ & $0.26^{\mathrm{a}}$ & $-0.39^{\mathrm{a}}$ \\
\hline TLTM $(\mathrm{kg})$ & $0.39^{\mathrm{a}}$ & $0.18^{\mathrm{a}}$ & $0.31^{\mathrm{a}}$ & $0.31^{\mathrm{a}}$ & $0.24^{\mathrm{a}}$ & $0.30^{\mathrm{a}}$ & $-0.16^{\mathrm{a}}$ \\
\hline Chair stand test (reps) & - & - & $0.11^{\mathrm{b}}$ & $0.14^{\mathrm{a}}$ & $0.15^{\mathrm{a}}$ & $0.11^{\mathrm{b}}$ & $0.13^{\mathrm{b}}$ \\
\hline Arm curl test (reps) & - & - & $0.16^{\mathrm{a}}$ & $0.11^{\mathrm{b}}$ & $0.16^{\mathrm{a}}$ & $0.13^{\mathrm{b}}$ & - \\
\hline 6-Min walk test (m) & - & - & $0.11^{\mathrm{b}}$ & $0.11^{\mathrm{b}}$ & $0.14^{\mathrm{a}}$ & $0.10^{\mathrm{b}}$ & - \\
\hline 8-Ft up-and-go test (sec) & - & - & - & - & - & - & - \\
\hline Fracture history (\#) & $-0.19^{\mathrm{a}}$ & $-0.18^{\mathrm{a}}$ & $-0.15^{\mathrm{a}}$ & $-0.18^{\mathrm{a}}$ & $-0.14^{\mathrm{b}}$ & $-0.20^{\mathrm{a}}$ & - \\
\hline Dietary Calcium (mg/day) & - & - & - & - & - & - & - \\
\hline Smoking (units) & $-0.15^{\mathrm{a}}$ & $-0.13^{\mathrm{b}}$ & - & - & $-0.12^{\mathrm{b}}$ & $-0.11^{\mathrm{b}}$ & - \\
\hline Medication (units) & - & $-0.12^{\mathrm{b}}$ & - & - & - & - & - \\
\hline \multicolumn{8}{|l|}{ Women } \\
\hline Age (years) & $-0.39^{\mathrm{a}}$ & $-0.25^{\mathrm{a}}$ & $-0.44^{\mathrm{a}}$ & $-0.39^{\mathrm{a}}$ & $-0.44^{\mathrm{a}}$ & $-0.43^{\mathrm{a}}$ & $-0.16^{\mathrm{a}}$ \\
\hline Height $(\mathrm{cm})$ & $0.40^{\mathrm{a}}$ & $0.31^{\mathrm{a}}$ & $0.43^{\mathrm{a}}$ & $0.36^{\mathrm{a}}$ & $0.38^{\mathrm{a}}$ & $0.35^{\mathrm{a}}$ & - \\
\hline $\mathrm{BM}(\mathrm{kg})$ & $0.53^{\mathrm{a}}$ & $0.40^{\mathrm{a}}$ & $0.35^{\mathrm{a}}$ & $0.51^{\mathrm{a}}$ & $0.26^{\mathrm{a}}$ & $0.47^{\mathrm{a}}$ & $-0.33^{\mathrm{a}}$ \\
\hline TFM $(\mathrm{kg})$ & $0.49^{\mathrm{a}}$ & $0.36^{\mathrm{a}}$ & $0.31^{\mathrm{a}}$ & $0.49^{\mathrm{a}}$ & $0.25^{\mathrm{a}}$ & $0.44^{\mathrm{a}}$ & $-0.33^{\mathrm{a}}$ \\
\hline TLTM $(\mathrm{kg})$ & $0.48^{\mathrm{a}}$ & $0.32^{\mathrm{a}}$ & $0.34^{\mathrm{a}}$ & $0.46^{\mathrm{a}}$ & $0.22^{\mathrm{a}}$ & $0.41^{\mathrm{a}}$ & $-0.22^{\mathrm{a}}$ \\
\hline Chair stand test (reps) & $0.12^{\mathrm{b}}$ & - & $0.16^{\mathrm{a}}$ & $0.13^{\mathrm{a}}$ & $0.17^{\mathrm{a}}$ & $0.15^{\mathrm{a}}$ & $0.12^{\mathrm{b}}$ \\
\hline Arm curl test (reps) & $0.23^{\mathrm{a}}$ & $0.16^{\mathrm{a}}$ & $0.28^{\mathrm{a}}$ & $0.24^{\mathrm{a}}$ & $0.26^{\mathrm{a}}$ & $0.26^{\mathrm{a}}$ & - \\
\hline 6-Min walk test $(\mathrm{m})$ & $0.15^{\mathrm{a}}$ & - & $0.25^{\mathrm{a}}$ & $0.23^{\mathrm{a}}$ & $0.27^{\mathrm{a}}$ & $0.23^{\mathrm{a}}$ & $0.16^{\mathrm{a}}$ \\
\hline 8-Ft up-and-go test (sec) & $-0.12^{\mathrm{b}}$ & - & $-0.22^{\mathrm{a}}$ & $-0.14^{\mathrm{a}}$ & $-0.22^{\mathrm{a}}$ & $-0.17^{\mathrm{a}}$ & $-0.18^{\mathrm{a}}$ \\
\hline Fracture history $(\mathrm{Y} / \mathrm{N})$ & $-0.22^{\mathrm{a}}$ & $-0.18^{\mathrm{a}}$ & $-0.17^{\mathrm{a}}$ & $-0.17^{\mathrm{a}}$ & $-0.17^{\mathrm{a}}$ & $-0.20^{\mathrm{a}}$ & $-0.15^{\mathrm{a}}$ \\
\hline Dietary Calcium (mg/day) & $0.11^{\mathrm{b}}$ & - & - & - & - & - & $0.11^{\mathrm{b}}$ \\
\hline Smoking (units) & - & - & - & - & - & - & - \\
\hline Medication (units) & - & - & - & - & - & - & $-0.12^{\mathrm{b}}$ \\
\hline
\end{tabular}

Only correlations that were statistically significant were included

$F N$ femoral neck, $L S$ lumbar spine, $B M$ body mass, TLTM total lean tissue mass, TFM total fat mass, reps repetitions, $Y / N$ yes/no

${ }^{\text {a }}$ Correlation is significant at 0.01 level (two-tailed)

${ }^{\mathrm{b}}$ Correlation is significant at 0.05 level (two-tailed)

Previous studies among postmenopausal women have shown an association between upper-body strength and LS $[12,31]$, hip [12, 32], and total body BMD [12, 33]. Some studies have considered biologically plausible, the association between upper-body strength and BMD at more distant sites like the hip and LS. Snow-Harter et al. [34] have proposed that muscle groups more distant to the LS, proximal femur, and total body may contribute to increased BMD in those areas because arm activity is linked to the simultaneous contraction of trunk-stabilizing muscles that directly exert forces on the hip and LS. In our study, results from the MLR analyses indicated that of the FF parameters, upper-body strength made the strongest contribution to the explained variation in FN BMD $(\beta=0.10, p<0.012)$, when the variance explained by all other variables in the model was controlled for. However, no other contribution from upper-body strength was evident for LS and total body BMD or for FSI.

The association between aerobic endurance and bone health/strength seems to be equivocal. In contrast to our results, Stewart et al. [12] did not find any significant correlation between aerobic fitness, measured directly as $\mathrm{VO} 2$ max, and BMD at total body, FN, or LS in men or women. Bevier et al. [35] found a significant correlation between aerobic fitness (evaluated directly as $\mathrm{VO} 2$ max) and BMD at the LS in men, but not in women. The lack of significant correlation between aerobic fitness and FN, trochanter, Ward's triangle, and LS BMD was also confirmed by Huuskonen et al. [36] and Miller et al. [14] for total body BMD. 
Table 4 Standard MLR between FN, LS, total body, and FSI and putative predictors (sex, age, BM, height, TLTM, TFM, 6-min walk test, arm curl test, chair stand test, 8 -ft up-and-go test); FN BMD $\left(R_{\text {adj }}^{2}=0.346\right)$

\begin{tabular}{lrrrrrr}
\hline Predictors & \multicolumn{1}{l}{$\begin{array}{l}\text { Crude } \\
\mathrm{B} \pm \mathrm{SE}\end{array}$} & $\begin{array}{l}\text { Adjusted } \\
\mathrm{B} \pm \mathrm{SE}\end{array}$ & Beta & \multicolumn{1}{c}{$p$} & 95 \% CI & $\begin{array}{l}\text { Increase/decrease } \\
\text { in FN BMD }\end{array}$ \\
\hline Sex (0 men, 1 women) & $-0.116 \pm 0.010$ & $-0.045 \pm 0.017$ & -0.153 & 0.008 & $-0.078,-0.012$ & $-{ }^{\mathrm{b}}$ \\
Height (cm) & $0.008 \pm 0.001$ & $0.003 \pm 0.001$ & 0.203 & $<0.001$ & $0.002,0.005$ & $0.051^{\mathrm{c}}$ \\
TLTM (kg) & $0.008 \pm 0.001$ & $0.000 \pm 0.001$ & 0.027 & 0.741 & $-0.002,0.003$ & $0.007^{\mathrm{d}}$ \\
BM (kg) & $0.005 \pm 0.000$ & $0.002 \pm 0.001$ & 0.191 & $<0.001$ & $0.001,0.003$ & $0.024^{\mathrm{e}}$ \\
Age (years) & $-0.008 \pm 0.001$ & $-0.006 \pm 0.001$ & -0.233 & $<0.001$ & $-0.008,-0.004$ & $-0.088^{\mathrm{f}}$ \\
6-Min walk test (m) & $0.000 \pm 0.000$ & $4.197^{-5} \pm 0.000$ & 0.033 & 0.422 & $0.000,0.000$ & $0.004^{\mathrm{g}}$ \\
Arm curl test (reps) & $0.008 \pm 0.001$ & $0.004 \pm 0.001$ & 0.101 & 0.012 & $0.001,0.006$ & $0.019^{\mathrm{h}}$ \\
Chair stand test (reps) & $0.006 \pm 0.001$ & $0.000 \pm 0.002$ & -0.006 & 0.893 & $-0.003,0.003$ & $-0.001^{\mathrm{i}}$ \\
8-Ft up-and-go test (sec) & $-0.010 \pm 0.002$ & $0.001 \pm 0.002$ & 0.017 & 0.658 & $-0.004,0.006$ & $0.004^{\mathrm{j}}$ \\
\hline
\end{tabular}

$B M$ body mass, TLTM total lean tissue mass

${ }^{a}$ Per additional increase/decrease in predictors

${ }^{\mathrm{b}} 116 \mathrm{mg} / \mathrm{cm}^{3}$ decrease in FN BMD for women in comparison to men

${ }^{\mathrm{c}} 51 \mathrm{mg} / \mathrm{cm}^{3}$ increase in FN BMD per additional $10 \mathrm{~cm}$ in height

d $7 \mathrm{mg} / \mathrm{cm}^{3}$ increase in FN BMD per additional $10 \mathrm{~kg}$ in TLTM

${ }^{\mathrm{e}} 24 \mathrm{mg} / \mathrm{cm}^{3}$ increase in FN BMD per additional $10 \mathrm{~kg}$ in BM

${ }^{\mathrm{f}} 88 \mathrm{mg} / \mathrm{cm}^{3}$ decrease in FN BMD per additional 5 years in age

$\mathrm{g}_{4} \mathrm{mg} / \mathrm{cm}^{3}$ increase in FN BMD per additional $100 \mathrm{~m}$ in 6-min walk

${ }^{\mathrm{h}} 19 \mathrm{mg} / \mathrm{cm}^{3}$ increase in FN BMD per additional five repetitions in arm curl

${ }^{\mathrm{i}} 1 \mathrm{mg} / \mathrm{cm}^{3}$ decrease in FN BMD per additional five repetitions decrease in chair stand

${ }^{\mathrm{j}} 4 \mathrm{mg} / \mathrm{cm}^{3}$ increase in FN BMD per additional $5 \mathrm{~s}$ in 8 - $\mathrm{ft}$ up-and-go

Table 5 Standard MLR between FN, LS, total body, and FSI and putative predictors (sex, age, BM, height, TLTM, TFM, 6-min walk test, arm curl test, chair stand test, 8-ft up-and-go test $)$; LS BMD $\left(R^{2}{ }_{\text {adj }}=0.274\right)$

\begin{tabular}{lrrrrrr}
\hline Predictors & $\begin{array}{l}\text { Crude } \\
B \pm \mathrm{SE}\end{array}$ & $\begin{array}{l}\text { Adjusted } \\
B \pm \mathrm{SE}\end{array}$ & Beta & \multicolumn{1}{c}{$p$} & 95 \% CI & $\begin{array}{l}\text { Increase/decrease } \\
\text { in LS BMD }\end{array}$ \\
\hline Sex (0 men, 1 women) & $-0.186 \pm 0.022$ & $-0.159 \pm 0.027$ & -0.360 & $<0.001$ & $-0.212,-0.107$ & $-{ }^{\mathrm{b}}$ \\
TLTM (kg) & $0.012 \pm 0.001$ & $-0.005 \pm 0.002$ & -0.205 & 0.016 & $-0.009,-0.001$ & $-0.213^{\mathrm{c}}$ \\
Height (cm) & $0.011 \pm 0.001$ & $0.004 \pm 0.001$ & 0.157 & 0.007 & $0.001,0.007$ & $0.062^{\mathrm{d}}$ \\
BM (kg) & $0.007 \pm 0.001$ & $0.006 \pm 0.001$ & 0.342 & $<0.001$ & $0.004,0.008$ & $0.067^{\mathrm{e}}$ \\
6-Min walk test (m) & $0.000 \pm 0.000$ & $-8.831^{-5} \pm 0.000$ & -0.047 & 0.245 & $0.000,0.000$ & $-0.009^{\mathrm{f}}$ \\
Age (years) & $0.005 \pm 0.001$ & $-0.003 \pm 0.001$ & -0.081 & 0.015 & $-0.006,-0.001$ & $-0.048^{\mathrm{g}}$ \\
Arm curl test (reps) & $0.006 \pm 0.002$ & $0.002 \pm 0.002$ & 0.028 & 0.500 & $-0.003,0.006$ & $0.008^{\mathrm{h}}$ \\
Chair stand test (reps) & $0.005 \pm 0.002$ & $0.003 \pm 0.002$ & 0.049 & 0.296 & $-0.002,0.008$ & $0.014^{\mathrm{i}}$ \\
\hline
\end{tabular}

$B M$ body mass, TLTM total lean tissue mass

${ }^{\text {a }}$ Per additional increase/decrease in predictors

${ }^{\mathrm{b}} 186 \mathrm{mg} / \mathrm{cm}^{3}$ decrease in LS BMD for women in comparison to men

${ }^{\mathrm{c}} 51 \mathrm{mg} / \mathrm{cm}^{3}$ increase in FN BMD per additional $10 \mathrm{~cm}$ in height

${ }^{\mathrm{d}} 213 \mathrm{mg} / \mathrm{cm}^{3}$ decrease in LS BMD per additional $10 \mathrm{~kg}$ in TLTM

${ }^{\mathrm{e}} 62 \mathrm{mg} / \mathrm{cm}^{3}$ increase in LS BMD per additional $10 \mathrm{~cm}$ in height

${ }^{\mathrm{f}} 67 \mathrm{mg} / \mathrm{cm}^{3}$ increase in LS BMD per additional $10 \mathrm{~kg}$ in BM

$\mathrm{g} 9 \mathrm{mg} / \mathrm{cm}^{3}$ decrease in LS BMD per additional $100 \mathrm{~m}$ in 6-min walk

${ }^{\mathrm{h}} 48 \mathrm{mg} / \mathrm{cm}^{3}$ decrease in LS BMD per additional 5 years in age

${ }^{i} 8 \mathrm{mg} / \mathrm{cm}^{3}$ increase in LS BMD per additional five repetitions in arm curl

${ }^{\mathrm{j}} 14 \mathrm{mg} / \mathrm{cm}^{3}$ increase in LS BMD per additional five repetitions in chair stand 
Table 6 Standard MLR between FN, LS, total body, and FSI and putative predictors (sex, age, BM, height, TLTM, TFM, 6-min walk test, arm curl test, chair stand test, 8 -ft up-and-go test $)$; total body BMD $\left(R_{\text {adj }}^{2}=0.486\right)$

\begin{tabular}{lrrrrrr}
\hline Predictors & \multicolumn{1}{l}{$\begin{array}{l}\text { Crude } \\
\mathrm{B} \pm \mathrm{SE}\end{array}$} & $\begin{array}{l}\text { Adjusted } \\
\mathrm{B} \pm \mathrm{SE}\end{array}$ & Beta & \multicolumn{1}{l}{$p$} & 95 \% CI & $\begin{array}{l}\text { Increase/decrease in } \\
\text { total body BMD }\end{array}$ \\
\hline Sex (0 men, 1 women) & $-0.137 \pm 0.007$ & $-0.071 \pm 0.012$ & -0.296 & $<0.001$ & $-0.095,-0.047$ & $-{ }^{\mathrm{b}}$ \\
TLTM (kg) & $0.009 \pm 0.000$ & $0.001 \pm 0.001$ & 0.076 & 0.283 & $-0.001,0.003$ & $0.015 \mathrm{c}$ \\
Height (cm) & $0.008 \pm 0.000$ & $0.001 \pm 0.001$ & 0.103 & 0.032 & $0.000,0.003$ & $0.020^{\mathrm{d}}$ \\
BM (kg) & $0.005 \pm 0.000$ & $0.003 \pm 0.000$ & 0.332 & $<0.001$ & $0.002,0.004$ & $0.032^{\mathrm{e}}$ \\
Age (years) & $-0.004 \pm 0.001$ & $-0.003 \pm 0.001$ & -0.127 & $<0.001$ & $-0.004,-0.002$ & $-0.037^{\mathrm{f}}$ \\
6-Min walk test (m) & $0.000 \pm 0.000$ & $1.048^{-6} \pm 0.000$ & 0.001 & 0.978 & $0.000,0.000$ & $0.001^{\mathrm{g}}$ \\
Chair stand test (reps) & $0.004 \pm 0.001$ & $0.001 \pm 0.001$ & 0.045 & 0.178 & $-0.001,0.003$ & $0.006^{\mathrm{h}}$ \\
8-Ft up-and-go test (sec) & $-0.007 \pm 0.002$ & $-0.001 \pm 0.002$ & -0.020 & 0.566 & $-0.004,0.002$ & $-0.004^{\mathrm{i}}$ \\
\hline
\end{tabular}

BM body mass, TLTM total lean tissue mass

${ }^{a}$ Per additional increase/decrease in predictors

${ }^{b} 137 \mathrm{mg} / \mathrm{cm}^{3}$ decrease in LS BMD for women in comparison to men

${ }^{\mathrm{c}} 15 \mathrm{mg} / \mathrm{cm}^{3}$ increase in total body BMD per additional $10 \mathrm{~kg}$ in TLTM

${ }^{\mathrm{d}} 20 \mathrm{mg} / \mathrm{cm}^{3}$ increase in total body BMD per additional $10 \mathrm{~cm}$ in height

e $32 \mathrm{mg} / \mathrm{cm}^{3}$ increase in total body BMD per additional $10 \mathrm{~kg}$ in BM

${ }^{\mathrm{f}} 37 \mathrm{mg} / \mathrm{cm}^{3}$ decrease in total body BMD per additional 5 years in age

$\mathrm{g} 1 \mathrm{mg} / \mathrm{cm}^{3}$ increase in total body BMD per additional $100 \mathrm{~m}$ in 6-min walk

${ }^{\mathrm{h}} 6 \mathrm{mg} / \mathrm{cm}^{3}$ increase in total body BMD per additional five repetitions in chair stand

${ }^{\mathrm{i}} 4 \mathrm{mg} / \mathrm{cm}^{3}$ decrease in total body BMD per additional $5 \mathrm{~s}$ in 8 - $\mathrm{ft}$ up-and-go

Our results agree, however, with those of Pocock et al. [23], who found a positive correlation between cardiorespiratory endurance (measured as $\mathrm{VO}_{2}$ max consumption) and $\mathrm{BMD}$ at the femur $(0.40<r<0.56, p<0.001)$. Vico et al. [22], in a sample of 55 women aged $73.54 \pm 5.9$ years old, found that cardiorespiratory endurance was a major determinant of FN

Table 7 Standard MLR between FN, LS, total body, and FSI and putative predictors (sex, age, BM, height, TLTM, TFM, 6-min walk test, arm curl test, chair stand test, 8 -ft up-and-go test); FSI $\left(R^{2}{ }_{\text {adj }}=0.215\right)$

\begin{tabular}{llrrrrr}
\hline Predictors & $\begin{array}{l}\text { Crude } \\
B \pm \mathrm{SE}\end{array}$ & $\begin{array}{l}\text { Adjusted } \\
B \pm \mathrm{SE}\end{array}$ & Beta & $p$ & 95\% CI & $\begin{array}{l}\text { Increase/decrease in } \\
\text { total body BMD }\end{array}$ \\
\hline Sex (0 men, 1 women) & $-0.278 \pm 0.33$ & $-0.182 \pm 0.061$ & -0.189 & 0.003 & $-0.302,-0.062$ & $-{ }^{\mathrm{b}}$ \\
TFM (kg) & $-0.024 \pm 0.002$ & $-0.011 \pm 0.005$ & -0.189 & 0.021 & $-0.020,-0.002$ & $-0.129^{\mathrm{c}}$ \\
BM (kg) & $-0.008 \pm 0.001$ & $-0.009 \pm 0.003$ & -0.232 & 0.009 & $-0.015,-0.002$ & $-0.106^{\mathrm{d}}$ \\
Height (cm) & $0.010 \pm 0.002$ & $0.008 \pm 0.003$ & 0.142 & 0.016 & $0.001,0.014$ & $0.130^{\mathrm{e}}$ \\
6-Min walk test (m) & $0.001 \pm 0.000$ & $-1.008^{-5} \pm 0.000$ & -0.002 & 0.957 & $0.000,0.000$ & $-0.001^{\mathrm{f}}$ \\
Chair stand test (reps) & $0.018 \pm 0.004$ & $0.010 \pm 0.005$ & 0.083 & 0.042 & $0.000,0.019$ & $0.057^{\mathrm{g}}$ \\
8-Ft up-and-go test (sec) & $-0.022 \pm 0.007$ & $0.007 \pm 0.008$ & 0.035 & 0.419 & $-0.010,0.023$ & $0.032^{\mathrm{h}}$ \\
Age (years) & $-0.006 \pm 0.003$ & $-0.008 \pm 0.003$ & -0.088 & 0.012 & $-0.013,-0.002$ & $-0.120^{\mathrm{i}}$ \\
\hline
\end{tabular}

$B M$ body mass, TFM total fat mass

${ }^{\text {a }}$ Per additional increase/decrease in predictors

${ }^{b} 278 \mathrm{mg} / \mathrm{cm}^{3}$ decrease in LS BMD for women in comparison to men

${ }^{\mathrm{c}} 129 \mathrm{mg} / \mathrm{cm}^{3}$ decrease in FSI per additional $10 \mathrm{~kg}$ in TFM

${ }^{\mathrm{c}} 106 \mathrm{mg} / \mathrm{cm}^{3}$ decrease in FSI per additional $10 \mathrm{~kg}$ in BM

${ }^{\mathrm{d}} 130 \mathrm{mg} / \mathrm{cm}^{3}$ increase in FSI per additional $10 \mathrm{~cm}$ in height

${ }^{\mathrm{e}} 1 \mathrm{mg} / \mathrm{cm}^{3}$ decrease in FSI per additional $100 \mathrm{~m}$ in 6-min walk

${ }^{\mathrm{f}} 57 \mathrm{mg} / \mathrm{cm}^{3}$ increase in FSI per additional five repetitions in chair stand

${ }^{\mathrm{g}} 32 \mathrm{mg} / \mathrm{cm}^{3}$ increase in FSI per additional $5 \mathrm{~s}$ in 8-ft up-and-go

${ }^{\mathrm{h}} 120 \mathrm{mg} / \mathrm{cm}^{3}$ decrease in FSI per additional 5 years in age 
BMD. In our study, although aerobic endurance was associated with BMD at multiple body sites and FSI, these associations vanished when other putative determinants were taken into account in the MLR analysis.

The relationship between balance and BMD has been studied mostly in older women [13, 30, 37-39] and, to our knowledge, few studies have investigated this relationship in men. Corroborating our data, Taaffe et al. [10] did not find any association between balance and hip BMD in elderly men. The association between balance and BMD found in our women agrees with the results found by Lindsey et al. [13] but are counter to those reported by Taaffe et al. [10] for elderly women. Lindsey et al. [13] also report a positive relationship between balance and BMD at the hip $(r=0.21, p<0.02)$ and total body $(r=0.21, p<0.02)$. Similarly, Khanzzani et al. [38] identified positive associations between BMD at multiple body sites and the get-up-and-go test $(-0.13<r<0.20, p<0.005-0.001)$, whereas Marin et al. [30] reported a specific positive association between static balance (measured as unipedal balance test) and LS BMD $(r=0.24, p<0.005)$ in older women. Additionally, Kärkkäinen et al. [37] even after controlling for other putative determinants, showed that the standing-one-foot was associated with LS BMD $\left(r^{2}=0.16, p=0.004\right)$ and BMD at the femoral regions $\left(0.17<r^{2}<0.23, p<0.001\right)$. As FF tests are related to falls, those with poorer performance scores on these tests may be at a greater risk of falls [40]. Further, if BMD is compromised, they would be at an increased risk of fracture, once a fall takes place. Since older women seem to be a group with enhanced risk for falls, a targeted intervention aimed at improving balance, muscular strength, and aerobic endurance should be considered in a preventative perspective for enhancement of health care in this specific subgroup of elderly.

In the present study, as hypothesized, FF tests are associated with BMD at multiple body sites and with FSI. However, after controlling for other constitutive predictors (sex, age, height, BM, TFM, and TLTM), FF had a minor contribution only in prediction of BMD at multisites and FSI. In agreement with our findings, other studies have shown that age [41], height [42], BM [30], TFM [19, 43], and TLTM $[35,44]$ are important predictors of BMD in the elderly. Results from MLR analyses, in our study, showed that sex, age, height, BM, and TLTM entered as the primary and most significant contributors to the variability in bone health/strength variables, with their relative importance varying by specific bone site: e.g., FN BMD (3-23\%), LS BMD (8-36 \%), and total body BMD (8-33\%).

In terms of clinical significance, our results showed an increase in FN, LS, and total body BMD of 24, 67, and $32 \mathrm{mg} / \mathrm{cm}^{3}$, respectively, per each additional $10 \mathrm{~kg}$ of BM. Similarly, per additional $10 \mathrm{~cm}$ of height, we identified an increase of 51,62 , and $20 \mathrm{mg} / \mathrm{cm}^{3}$ in FN, LS, and total body
BMD, respectively. On the other hand, per each additional 5 years of age, we found a decrease of 88,48 , and $37 \mathrm{mg} /$ $\mathrm{cm}^{3}$ in FN, LS, and total body BMD, respectively. Also, we detected a decrease of 116,186 , and $137 \mathrm{mg} / \mathrm{cm}^{3}$ in FN, LS, and total body BMD, respectively, for women in comparison to men.

The mechanism whereby bone behaves is complex and is determined by a speculative network of interactions influenced by factors such as PA, genetics, growth factors, gender, age, soft tissue composition (TLTM, TFM), lifestyle choices (smoking, alcohol intake), medication, hormones, and nutrition [45]. In our study, the association between FF and BMD, at multiple sites and FSI, vanish mostly when size and body composition are taken into account. These results suggest that the mechanism by which BMD and FSI are affected is mediated by bone's response to local mechanical loading. In this perspective, muscle forces are the primary source of stress (external force) causing strain (the relative change in length of bone, or deformation of bone tissue that occurs with loading). The stimulus for bone functional adaptation (mechanotransduction) is the customary strain stimulus defined by Skerry [46], that is both sex and site specific, and it is genetically, biochemically, and pharmacologically modifiable. Another pathway through which muscles can influence bone is by an increase TLTM and this again places a large external load on the entire skeleton, resulting in higher bone strains.

Some limitations of our study should be noted. Our study had a cross-sectional study design, reflecting associations but not revealing causality. In addition, all participants must have been able to walk without assistance or aid of other persons and were therefore in good overall health. Generalizability of our findings to less mobile populations of ARM and less healthy or institutionalized groups is not possible. The strengths of our study are the large population-based sample and extensive bone and physical measurements.

In sum, all BMD body sites were significantly negatively correlated with age, and fracture history in men and women. The MLR analyses confirmed that women and older people had lower BMD and FSI. Lower body strength made the strongest contribution to explaining FSI, when the influence of all other variables in the model was controlled. Sex, age, height, BM, TLTM, and TFM entered as the primary and most significant contributors for BMD at the multiple body sites and for FSI. Although, body strength, endurance, and balance should be considered in clinical assessments of bone health in older people, our findings suggest that body size and body composition have a higher relevance in the explanation of BMD in older people.

Acknowledgments The authors are grateful to Bruna Gouveia, Ercília Fena, Joana Castro, Letícia Sousa and Sílvio Velosa for technical assistance in the collection of the sample and data management. This 
study was supported by doctoral degree grants from Fundação para a Ciência e a Tecnologia reference: SFRH/BD/29300/2006. The dualenergy X-ray absorptiometry (DXA) scans were generously sponsored by Iberdata Equipment's S.A. Technical assistance in collection of the data was supported by Madeira Regional Government and Regional Secretary of Education and Culture.

\section{Conflicts of interest None.}

\section{References}

1. Stock H, Schneider A, Strauss E (2004) Osteoporosis: a disease in men. Clin Orthop 425:143-151

2. U.S. Department of Health and Human Services (2004) Bone health and osteoporosis: a report of the Surgeon General. U.S. Department of Health and Human Services, Office of the Surgeon General, Rockville

3. Kelly PJ, Eisman JA, Sambrook PN (1990) Interaction of genetic and environmental influences on peak bone density. Osteoporos Int $1: 56-60$

4. Heinonen A (2001) Biomechanics. In: Khan K, McKay H, Kannus P, Bailey D, Wark J, Bennell K (eds) Physical activity and bone health. Human Kinetics, Champaign, pp 23-34

5. Slemenda CW, Miller JZ, Hui SL, Reister TK, Johnston CC (1991) Role of physical activity in the development of skeletal mass in children. J Bone Miner Res 6:1227-1233

6. Babaroutsi E, Magkos F, Manios Y, Sidossis LS (2005) Body mass index, calcium intake, and physical activity affect calcaneal ultrasound in healthy Greek males in an age-dependent and parameter specific manner. J Bone Miner Metab 23:157-166

7. Schott AM, Cormier C, Hans D, Favier F, Hausherr E, DargentMolina P, Delmas PD, Ribot C, Sebert JL, Breart G, Meunier PJ (1998) How hip and whole body bone mineral density predict hip fracture in elderly women. The EPIDOS prospective study. Osteoporos Int 8:247-254

8. Nguyen T, Sambrook P, Kelly P, Jones G, Lord S, Freund J, Eisman J (1993) Prediction of osteoporotic fractures by postural instability and bone density. BMJ 307:1111-1115

9. Aoyagi K, Ross PD, Hayashi T, Okano K, Moji K, Sasayama H, Yahata Y, Takemoto T (2000) Calcaneus bone mineral density is lower among men and women with lower physical performance. Calcif Tissue Int 67:106-110

10. Taaffe DR, Simonsick EM, Visser M, Volpato S, Nevitt MC, Cauley JA, Tylavsky FA, Harris TB, Health ABC Study (2003) Lower extremity physical performance and hip bone mineral density in elderly black and white men and women: cross-sectional associations in the Health ABC Study. J Gerontol A Biol Sci Med Sci 58:934-942

11. Hughes VA, Frontera WR, Dallal GE, Lutz KJ, Fisher EC, Evans WJ (1995) Muscle strength and body composition: associations with bone density in older subjects. Med Sci Sports Exerc 27:967974

12. Stewart KJ, Deregis JR, Turner KL, Bacher AC, Sung J, Hees PS, Tayback M, Ouyang P (2002) Fitness, fatness and activity as predictors of bone mineral density in older persons. J Intern Med 252:381-388

13. Lindsey C, Brownbill RA, Bohannon RA, Ilich JZ (2005) Association of physical performance measures with bone mineral density in postmenopausal women. Arch Phys Med Rehabil 86(6):11021107

14. Miller LE, Pierson LM, Pierson ME, Kiebzak GM, Ramp WK, Herbert WG, Cook JW (2009) Age influences anthropometric and fitness-related predictors of bone mineral in men. Aging Male 12 $(2-3): 47-53$
15. Harris S, Dallal GE, Dawson-Hughes B (1992) Influence of body weight on rates of change in bone density of the spine, hip and radius of postmenopausal women. Calcif Tissue Int 50:19-23

16. Edelstein SL, Barrett-Connor E (1993) Relation between body size and bone mineral density in elderly men and women. Am J Epidemiol 138:160-169

17. Visser M, Kiel DP, Langlois J, Hannan MT, Felson DT, Wilson PW, Harris TB (1998) Muscle mass and fat mass in relation to bone mineral density in very old men and women: the Framingham Heart Study. Appl Radiat Isot 49:745-747

18. Hagberg JM, Zmuda JM, McCole SD, Rodgers KS, Ferrell RE, Wilund KR, Moore GE (2001) Moderate physical activity is associated with higher bone mineral density in postmenopausal women. J Am Geriatr Soc 49:1411-1417

19. Pluijm SM, Visser M, Smit JH, Popp-Snijders C, Roos JC, Lips P (2001) Determinants of bone mineral density in older men and women: body composition as mediator. J Bone Miner Res 16:2142-2151

20. Cawthon PM, Fullman RL, Marshall L, Mackey DC, Fink HA, Cauley JA, Cummings SR, Orwoll ES, Ensrud KE, Osteoporotic Fractures in Men (MrOS) Research Group (2008) Physical performance and risk of hip fractures in older men. J Bone Miner Res 23 (7):1037-1044

21. Blain H, Vuillemin A, Teissier A, Hanesse B, Guillemin F, Jeandel C (2001) Influence of muscle strength and body weight and composition on regional bone mineral density in healthy women aged 60 years and over. Gerontology 47(4):207-212

22. Vico L, Pouget JF, Calmels P, Chatard JC, Rehailia M, Minaire P, Geyssant A, Alexandre C (1995) The relations between physical ability and bone mass in women aged over 65 years. J Bone Miner Res 10(3):374-383

23. Pocock N, Eisman J, Gwinn T, Sambrook P, Kelly P, Freund J, Yeates M (1989) Muscle strength, physical fitness, and weight but not age predict femoral neck bone mass. J Bone Miner Res 4 (3):441-448

24. Instituto Nacional de Estatística (2002) Censos 2001: resultados definitivos: XIV recenseamento geral da população: IV recenseamento geral da habitação. Instituto Nacional de Estatística, Lisboa

25. Yoshikawa T, Turner CH, Peacock M, Slemenda CW, Weaver CM, Teegarden D, Markwardt P, Burr DB (1994) Geometric structure of the femoral neck measured using dual-energy X-ray absorptiometry. J Bone Miner Res 9:1053-1064

26. Rikli RE, Jones CJ (2001) Senior fitness test manual. Development and validation of a functional fitness test for community-residing older adults. Human Kinetics, Champaign

27. Rose D (2003) Fallproof: a comprehensive balance and mobility training program. Human Kinetics, Champaign

28. Lopes C (2000) Reproducibility and validity of a semi-quantitative food frequency questionnaire. Dissertation. University of Porto

29. SPSS (2010) Statistical Package for the Social Sciences. Version 17.0. SPSS Inc, Chicago

30. Marin RV, Pedrosa MA, Moreira-Pfrimer LD, Matsudo SM, Lazaretti-Castro M (2010) Association between lean mass and handgrip strength with bone mineral density in physically active postmenopausal women. J Clin Densitom 13(1):96-101

31. Kröger H, Tuppurainen M, Honkanen R, Alhava E, Saarikoski S (1994) Bone mineral density and risk factors for osteoporosis a population-based study of 1600 perimenopausal women. Calcif Tissue Int 55(1):1-7

32. Kritz-Silverstein D, Barrett-Connon E (1994) Grip strength and bone mineral density in older women. J Bone Miner Res 9:45-51

33. Proctor DN, Melton LJ III, Khosla S, Crowson CS, O'Connor MK, Riggs BL (2000) Relative influence of physical activity, muscle mass and strength on bone density. Osteoporos Int 11:944-952

34. Snow-Harter C, Bouxsein M, Lewis B, Charette S, Weinstein P, Marcus R (1990) Muscle strength as a predictor of bone mineral density in young women. J Bone Miner Res 5:589-595 
35. Bevier WC, Wiswell RA, Pyka G, Kozak KC, Newhall KM, Marcus R (1989) Relationship of body composition, muscle strength, and aerobic capacity to bone mineral density in older men and women. J Bone Miner Res 4(3):421-432

36. Huuskonen J, Vaisanen SB, Kroger H, Jurvelin C, Bouchard C, Alhava E, Rauramaa R (2000) Determinants of bone mineral density in middle aged men: a population-based study. Osteoporos Int 11:702-708

37. Kärkkäinen M, Rikkonen T, Kröger H, Sirola J, Tuppurainen M, Salovaara K, Arokoski J, Jurvelin J, Honkanen R, Alhava E (2009) Physical tests for patient selection for bone mineral density measurements in postmenopausal women. Bone 44(4):660-665

38. Khazzani H, Allali F, Bennani L, Ichchou L, El Mansouri L, Abourazzak FE, Abouqal R, Hajjaj-Hassouni N (2009) The relationship between physical performance measures, bone mineral density, falls, and the risk of peripheral fracture: a cross-sectional analysis. BMC Publ Health 9:297

39. Sakai A, Toba N, Takeda M, Suzuki M, Abe Y, Aoyagi K, Nakamura T (2009) Association of unipedal standing time and bone mineral density in community-dwelling Japanese women. Osteoporos Int 20(5):731-736

40. Toraman A, Ün Yıldırım N (2009) The falling risk and physical fitness in older people. Arch Gerontol Geriatr 51(2):222-226
41. Hannan MT, Felson DT, Dawson-Hughes B, Tucker KL, Cupples LA, Wilson PW, Kiel DP (2000) Risk factors for longitudinal bone loss in elderly men and women: the Framingham Osteoporosis Study. J Bone Miner Res 15:710-720

42. Bunout D, Barrera G, de la Maza MP, Leiva L, Gattas V, Hirsch S (2007) Height reduction, determined using knee height measurement as a risk factor or predictive sign for osteoporosis in elderly women. Nutrition 23(11-12):794-797

43. Taaffe DR, Cauley JA, Danielson M, Nevitt MC, Lang TF, Bauer DC, Harris TB (2001) Race and sex effects on the association between muscle strength, soft tissue, and bone mineral density in healthy elders: the Health, Aging, and Body Composition Study. J Bone Miner Res 16(7):1343-1352

44. Travison TG, Araujo AB, Esche GR, Beck TJ, McKinlay JB (2008) Lean mass and not fat mass is associated with male proximal femur strength. J Bone Miner Res 23:189-198

45. Khan K, McKay H, Kannus P, Bailey D, Wark J, Bennell K (2001) Physical activity and bone health. Human Kinetics, Champaign

46. Skerry T (2006) One mechanostat or many? Modifications of the site-specific response of bone to mechanical loading by nature and nurture. J Musculoskelet Neuronal Interact 6:122-127 